\title{
A alma do jurista *
}

\section{B. de Siqueira Ferreira}

Jovens colegas

Simbolicamente, estamos no limiar da velha Faculdade de Direito de São Paulo, nos humbrais desta esplêndida catedral que, plantada, ha mais de um século, no coração da Paulicéia, foi a primeira, com sua irmã gêmea do Recife, a irradiar a cultura jurídica pela Pátria e sempre foi, e será "a representação viva do Direito Nacional". (1).

Neste instante, das monacais Arcadas se despede mais uma plêiade de jovens cultores do Direito, ufanos dos laureis conquistados, filhos espirituais da tradicional Academia. A mim tocou-me a honra, meus jovens colegas, de vos dirigir a saudação de despedida.

Aqui estou, esmagado pela generosidade de vossa escolha, de todo em todo desacertada, de vosso convite que certamente recusaria si o cativante gesto não envolvesse, pela sua própria natureza, a simpatia, a amizade que entre nós, bem o sabeis, são recíprocas e não sentisse que, professor da Faculdade de Direito de São Paulo, na tribuna me sustentam as gloriosas tradições da nossa Casa.

Aqui estou, entre jubiloso e triste.

Jubiloso porque, identificado convosco, sinto o palpitar de vossos corações e dos entes que vos são queridos, porque me conquista a emoção de que vos achais possuidos,

( $\left.{ }^{\star}\right)$ Discurso do paraninfo à turma de bacharelandos de 1941, da Faculdade de Direito da Universidade de São Paulo, pronunciado em 5 de janeiro de 1942, na ceremônia da colação de gráu, realizada no. Teatro Municipal. 
como si fosse eu próprio que neste momento recebesse o honroso gráu.

Vejo-me transportado, graças a vós, a esta comunhão de sentimentos, á minha mocidade, ao dia em que daquí tambem partí, sentindo o que então sentí e agora novamente sinto, e que é o que vós sentís.

Jubiloso e triste...

Triste, sim, porque esta festa é tambem um Adeus, e nos momentos de despedida se engasta, desde logo, desde então, no coração do homem, o germem, a semente da Saudade...

Senhores Bachareis:

Que vos hei-de dizer neste instante, como poderei expressar os votos que são meus, de todos vossos Mestres, de toda a Academia, de que saibais sempre, nas horas felizes e calmas de bonança, como nas amargas e exaustivas de tempestade; honrar o nome que vos legaram vossos maiores, engrandecer a vossa, a nossa Faculdade, enaltecer o nosso São Paulo, dignificar a Pátria, o nosso Brasil?

Que vos hei-de dizer, não para vos animar, pois sois jovens cheios de entusiasmo, com mais ânimo e coragem, que eu, encanecido já pélos desenganos e asperezas da vida, não, pois, para vos animar a cumprir o destino que venho de esboçar e que é aquele a que naturalmente aspira quem parte desta Casa, mas tão somente para que vos lembreis de vosso modesto e obscuro professor de ontem, do vosso paraninfo, ao conquistardes as glórias a que fadado está todo sincero cultor do Direito?

Que vos hei-de dizer?

Não quero vos trair e, á guiza de despedida, reconduzir-vos á condição de alunos com mais uma das minhas desalinhavadas lições de direito...

Mas, por outro lado, como impedir o jurista de transpor suas sensações, os sentimentos que lhe vão nalma para a clave do Direito? 
Como não me referir á idéia do Direito que foi a que nos uniu durante três anos, longos para vós que ardentemente almejaveis o bacharelado e que para mim tão céleres deslisaram no vosso convívio?

Como esquecer o Direito, traço de união de nossas mentalidades?

Como olvidar o Direito nesta solenidade em que sois sagrados seus sacerdotes? em que vos vejo, em que nos vemos cheios de dignidade em suas vestes talares?

Como não cuidar do Direito, quando no mundo, "homo lupus hominis" se estraçalha - oh, ironia! — em nome do próprio Direito e esquecido que "Justitia hostes vincere gloriosus est quam armis", com a sua destruição acarreta a derrocada da Civilização, fruto de séculos de penoso labor de tantas gerações?

Sim; é em nome do Direito, entrevisto sob aspeto diverso, concebido por mentalidades irreconciliaveis, que o próprio Direito é vilipendiado, que a Liga das Nações, sonho de Wilson e que seria, como juiz dos Povos, o vértice do ângulo tal como concebe Pekelis (2) toda relação jurídica, se desmorona, ameaçando arrastar na avalanche todo o Direito Internacional.

Assistimos, perplexos e cheios de angústia e temor, a essa lucta de titans que ensanguenta quatro quintas partes da humanidade, avermelha os sete mares do globo e acende no planeta seus trágicos clarões ao norte e ao sul, tanto no oriente como no ocidente.

E' o embate gigantesco, senhores, de duas concepções jurídicas, a tremenda explosão de dois credos políticos que se entrechocam.

Democracia e totalitarismo.

Este, alicerçado no princípio da autoridade; aquele, no de liberdade; aquí, o Estado vivendo do Povo, para o Povo e pelo Povo que escolhe seus governantes - a teoria da representação, a teoria do eleito; ali, o chefe - führer, duce - a encarnar a vontade do Estado. 
"Vós sois a Alemanha; - diz, no Congresso de Nuremberg, o famoso Rudolf Hess - quando praticais qualquer ato, é a Nação que o pratica; quando julgais, é a Nação que julga" (3).

$\mathrm{Na}$ Itália, a exaltação do Estado, em que se percebe a inspiração na doutrina de HEGEL, conduz ao totalitarismo, porque no credo fascista, Ele - o Estado - é o Absoluto diante do qual os individuos e os grupos nada mais são que o Relativo (4).

$\mathrm{E}$, como corolario lógico, o partido único: totalitarismo é, na vèrdade, o regimen em que é criminosa toda oposição, ilícitos todos os partidos que não o do Estado ou seja o do Chefe.

Nitidamente aquí se observa o conhecido movimento pendular em todo seu exagêro: da desordem do após guerra de 1914, como consequência do desejo de paz e socego que animava todos os povos egressos da luta, a transformação do indivíduo, da personalidade humana em mera engrenagem da máquina do Estado, a mover-se, a viver, a pensar sob o impulso da mola mestra, do Chefe.

Mas não será isto a consagração da mais pura autocracia?

Desta se distingue o totalitarismo, ensina Manoilesco, pela sinceridade e desinteresse de seus chefes (5).

E', porém, de se perguntar - não vos parece - si mais sinceros não seriam os velhos monarcas absolutos hoje mergulhados na escuridão do passado, que acreditavam governar por direito divino? E quem demonstra mais ambição: o que nasce no trono ou aquele que escala o poder?

A verdade é que esta volta á autocracia é o prelúdio, o crepúsculo de uma nova noite medieval que tenta lançar seu negro manto sobre o mundo.

E contra esta nova ordem de coisas que se batem as Democracias, erguendo sempre o lábaro sagrado da liberdade, mas fugindo, por sua vez, lenta, mas seguramente, como convém, dos exageros do individualismo tal como se imputa 
a Escola Liberal que, por seu turno, era a desmedida reação operada em França em 1789, tal como fazia prever dois séculos antes a célebre carta anônima recebida por LuIz xIV e atribuida a FÉNELon em que se denunciava “o excesso do despostismo que abastardava e destruia as forças morais do país e o absolutismo politico anti-cristão de orgulho, de violência e de má fé (6).

o Estado não é um simples meio de seguränça individual, não deve exercer apenas funções de polícia, mas, bem compreendendo as deficiências da iniciativa particular, amenizar aquí e alí as asperezas, as arestas do egoismo individual.

Aquí e alí, sua intervenção se faz mistér para que a velha fórmula da igualdade dos cidadãos, essência da Democracia, seja realmente realizada em sua verdadeira significação que consiste em tratar com desigualdade coisas desiguais.

Daí esse direito novo, esse amparo ao fraco contra o forte, expressão lídima, em acertada medida, da Justiça, mas perigosa pelos exageros a que a orientação facilmente conduz.

Essa tendência para se dar um sentido social ao Direito, essa socialização do Direito é uma necessidade que se fez sempre sentir ao espírito dos grandes filósofos.

Já DANTe, esse Poeta de gênio, a revelava em sua célebre definição de direito como "realis ac personalis proportio hominis ad hominem quae servata, servat societatem, corrupta, corrumpit", germen da magistral síntese de Ardigó, e na qual certamente se abeberou Pedro Lessa para o ver como o conjunto de condições de vida e desenvolvimento do indivíduo e da sociedade.

Condições de vida e desenvolvimento do indivíduo e da sociedade, notai bem.

A dificuldade está em manter, em suas justas proporções, as relações do indivíduo com o todo social, com o Estado. 
Si sacrificar a socieđãde ao indivíduo nos repugna, não será mal maior o holocáusto da personalidade humana ao Estado?

Em recente artigo, o notavel pensador LuIz Recasens Siches, invocando o magnífico exemplo de "sir" Henry KNolly, faz luz sobre o assunto, ilumina o problema.

Em um prédio devorado por um incêndio se acha em perigo de vida uma criança de tenra idade e de destruição uma preciosa tela de Rubens. O tempo urge, as chamas avançam ameaçadoramente, não se póde salvar a ambos: a criança - o ser humano - e a maravilhosa obra de arte. A escolha se impõe, mas qualquer que seja definirá bem as nossas tendências, "todo o sentido da nossa cultura e com o mesmo a base fundamental de nossas idéias políticas." Sim. "Cultura é o conjunto, assevera o egregio professor de Santiago de Compostela, de todos os valores - Verdade, Beleza, Moralidade, Justiça, etc. - enquanto tendem a realizar-se em um substractum real determinado. Si este substractum da cultura é o homem, os valores supremos serão os morais; todos os demais aparecerão como meios cujo fim ultimo é a personalidade ética humana. A Ciência, a Arte, o Direito, a Pátria, o Estado terão as carateristicas de meios ou intrumentos postos a serviço do homem. Mas si entendermos, pelo contrário, que o substractum da cultura não é a personalidade humana, mas algo que está além do homém, ou seja a produção em si mesma de coisas objetivas valiosas, então a personalidade humana representará mero instrumento, para que se produzam tais objetos culturais: obras de arte, tratados científicos, Estados, etc..."

"A primeira das soluções representa uma doutrina personalista, a segunda a teoria transpersonalista. Quem opta pela salvação da criança se decide em favor do individualismo; quem prefere salvar o quadro abraça a tese transpersonalista. O partidário desta entenderá bem pago o Coliseu Romano com a miséria e sofrimento de milhões de escravos e jamais achará que o sacrificio de vidas foi bastante para que o Estado conquiste novas terras ou aumente seu poderio. 
O sacrifício do soldado não representará para o mesmo um ato de heroismo em defesa da idéia de Justiça, mas o justo preço que paga ao Estado pelos benefícios que este lhe traz". "Segundo esta concepção totalitária, "o homem é degradado a condição de simples massa plástica, a instrumento destinado a produzir obras culturais ou o engrandecimento e poder da coletividade, enquanto para o personálismo e para o individualismo tanto o Estado cómo a Ciência e a Arte serão os meios postos a serviço da individualidade humana, para que esta realize seus fins, tal como diz a Biblia: "o Estado por causa do homem foi feito" (7)

$\mathrm{Si}$ as condições sociais de hoje exigem solução para novos problemas, "si, como adverte Eduardo Espinola, ao sociólogo compete observar os fenômenos, perscrutar-lhes as cáusas e estudar-lhes os aspetos benéficos e adverșos para orientar e dirigir a política econômica, pertence ao jurista o papel relevante de desfazer os equívocos em torno das regras de conducta, relembrar a verdadeira noção de direito, trazer ás mentes desvairadas a compreensão jurídica do Estado e dos seus problemas, restaurar a dignidade da pessoa" (8).

Não ha nem deve haver pois, como quer Kralyevitch (9), "glissement du Droit vers la Sociologie", mas subordinação desta ao Direito.

A hora é a do jurista, como maravilhosamente se exprime Levy UlmanN.

Mas como poderá este cumprir sua missão, como podeis vós, caros e jovens colegas, separar o jôio do trigo, conhecer os justos limites desta tendência para um direito novo, se haver nesta "caccia all'ombra"?

Como, jovens, cheios de talento e de idealismo, mas faltos de experiência cujo alto preço é o sacrifício de nossa juventude, encontrar o caminho seguro, hoje que a velha fórmula medieval do "magister dixit" perdeu todo encantamento e mais não tem a virtude de pedra filosofal destinada a aferir verdades científicas? 
Qual hoje a pedra de toque, si neste cáos de doutrinas e tendências, todas reivindicam a primazia que compete somente á verdade?

Lembra Claude du Pasquier que o renascimento do Direito Natural se deve "á guerra de 1914 que deu á filosofia idealista do direito forte impulso por ter se infiltrado no campo dos Aliados a convicção de que se batiam pelo Direito." (10) Daí o desejo de elucidar esta noção abstrata, de verificar em que consistia esse direito que os iluminava e contra o qual ferozmente combatiam os Imperios Centrais.

Hoje, porém, que filão devemos explorar em busca da verdade?

Vamos encontrá-lo na própria Alemanha que nós bem sabemos o quão poderosa é pelo pensamento e pelas armas, mas - é bem de ver - sem que nos deslumbrem os exageros impostos pelo orgulho de seus chefes e pelas suas condições vitais que tanto diferem, mercê de Deus, das de nossa Pátria.

Foi na segunda sessão do Instituto Internacional de Filosofia do Direito e de Sociologia Jurídica que lançou Wilhelm Sauer, professor da Universidade de Münster, na Westphalia, a sua monumental concepção de um direito a três dimensões que tão bem explica a moderna Babel jurídica.

"A esta época em que se fala não mais e tão só duma transformação da concepção do Direito e do Estado, mas de uma crise geral do Direito e do Estado, oberva o filosofo alemão, mais que nunca se aplica a "boutade" tanta vez citada de Kant a propósito dos juristas que ainda estão a discutir a definição de direito. Este, certamente, evolue com a vida, podendo, pois, como consequência, ter estrutura radicalmente diferente sob a influência das condições de vida que variam entre os diversos povos ou no mesmo povo, em diversas épocas" (11).

E', como vedes, o reconhecimento da conhecida apóstrofe de Blaise Pascal: "Verité en deçá des Pyrenées, erreur au delá". 
Que dizer-se quando não os Pyrineos, mas o infindavel Atlântico separa paises e continentes?

"Mas, em sentido oposto, prossegue SAUER, creio poder demonstrar que o direito, justamente quando se o encara como direito vivo, possue uma estrutura essencial, que impõe seu reconhecimento universal. Tal acôrdo sôbre a essência do direito, como sendo uma das principais expressões da vida e das mais importantes necessidades da civilização, constitue condição preliminar indispensavel e, ao mesmo tempo, a melhor garantia do procurado acôrdo entre os povos".

E' este direito vivo, este direito que tem relêvo, este direito a três dimensões realmente a pedra de toque de que vos falei.

E' o direito que vive em nós e não deflue tão só da nossa formação jurídica em uma escola de direito, mas que anteriormente já vinha se sedimentando, se cristalizando, como parte integrante do nosso eu, no convivio dos da nossa raça, da nossa gente, do nosso lar.

E' 'em nossa casa natal que recebemos de nossos Páis a primeira lição de Justiça, a severidade desvelada do pái, mitigada pela bondade carinhosa e suave de nossa Mãe.

Na escola primária, a primeira mestra prossegue na tarefa abençoada de nos ambientar nas tradições de nossos ancestrais.

$\mathrm{E}$, assim, aos poucos, insensivelmente vai se formando o nosso carater, se aprimorando nosso sentimento de Justiça.

E' nesse terreno já trabalhado pela Religião, pela Moral, pelos Costumes que é semeada a cultura jurídica.

"A diferença entre o Direito, a Moral e os Costumes que os sistemas filosóficos acolhiam até este momento, pontifica Sauer, perde toda a sua importância do ponto de vista do direito vivo, pois os três ramos se tocam, se entrelaçam e se completam".

Eis porque "o estado jurídico de um povo não póde ser reconhecido pelo estudo de suas leis, nem mesmo pelo da atividade de seus funcionários, mas sim pelo das reais 
condições jurídicas da vida em comum. Estas traduzem o direito vivo, o direito real que desta maneira aparece plastỉcamente, "ad instar" de um corpo no espaço. O direito tem assim, ele próprio, três dimensões" (12).

Do jurista germânico, é bem de ver, só é aceitavel a concepção de um direito a três dimensões em suas linhas mestras, devendo nos acautelar, como advertiu Ricasens Siches, no mesmo congresso de filosofia, contra os exageros do "atual pensamento alemão que parece se resumir em um culto ao poder absoluto, sinão a uma ditadura pessoal que os juristas tedescos substituem á comunidade nacional - Volk - de que falam sem cessar; enquanto o traco caraterístico dos povos latinos é a sua tendência para um ideal moral" (13).

$\mathrm{E}$, realmente, SAuEr enfileira na mesma plana leis, decretos e a vontade do Führer e funda a obediência ás normas em uma disciplina voluntária e livre que decorre naturalmente do reconhecimento da necessidade do Estado e do valor cultural do Führer.

E' o Volkgeist, ensinam Siegert, Nicolar e outros, o espírito da Alemanha nórdica, da eterna Alemanha, a fonte primária do Direito, de que é supremo interprete o Führer inamovivel e irresponsavel, como salienta HaNs Frank (14).

Em nosso ambiente, em nosso clima é planta exótica que não vinga a hodierna orientação filosófica alemã, a mistica nacional socialista que fenece quando distanciada de seu meio natural, as margens embriagadoras do Reno bordadas pelo cenário fantasmagórico de suas cidades medievais.

E' fenômeno puramente germânico, como o fascismo, no dizer do próprio Mussolını, o é puramente italiano.

Mas, si como afirma o próprio SAUER, a concepção jurídica varia de acôrdo com as condições de vida dos povos, mal não ha que procuremos o conteudo entre nós do Direito a truês dimensões.

$\mathrm{Na}$ verdade, algures já escrevi eu próprio, que, si ha muito, Direito, Moral e Costumes se emanciparam da Reli- 
gião, que, si ha muito, tais normas deixaram de viver sob a égide da Fé qúe até então conduzia o mundo, não menos verdade é que continuam marcos diferentes, mas convergentes a orientar a humanidade.

E' do amálgama dessas normas que nasce em nós o sentimento de direito, de um direito palpitante e vivo que é a própria alma do jurista.

Nossas tradições leigas e religiosas, este imenso patrimônio que nos legaram nossos maiores é a matéria plástica que moldada nas escolas de direito, entre nós recebendo o sôpro vivificador das tradicionais Arcadas, vai formar a alma do jurista brasileiro.

"Apague-se a história das academias jurídicas do Brasil e a história da nação brasileira será um enigma", disse Pedro Lessa.

E' a nossa alma de juristas brasileiros que faz com que nos repugnem certas instituições, sinão jurídicas ao menos legais, certos moluscos legislativos, informes, gelatinosos, escorregadiços, indefinidos que lançam seus tentáculos a sugar as forças morais de uma nação.

E' esse direito vivo que nos adverte contra certas normas, verdadeiros abortos legislativos que todo sistema jurídico contém mas que encontram seu túmulo no próprio código que as albergou.

"O conteudo das leis, frisa notavel filósofo italiano, deve corresponder ás necessidades do povo. Uma lei não conforme á nossa índole ou aos nossos hábitos será respeitada, porque os juizes curam da sua execução, mas com artifícios todos procurarão evitá-la. Esta consideração tem cabimento - prossegue - principalmente hoje que á mania das reformas se junta a moda de copiar as das nações de maior nomeada" (15).

E a nossa alma do jurista que treme pela Pátria quando, nos momentos de comoção social, vê surgir uma legislação de afogadilho, vê brotarem verdadeiras "leges saturae" em 
que hoje se corrige o êrro que a pressa ditou na vespera, para novamente se errar no dia seguinte.

E a pujança do direito vivo que inculca o desdém a essa legislação obesa, de uma obesidade de alastrar estantes, de uma adiposidade balofa e doentia a trair a enfermidade que tenta em vão invadir o organismo social.

É essa alma a prêsa da nevrose que hoje a tantos tortura, oriunda da instabilidade das leis alma, á que faz éco à advertência de GoGL1OLo: "A observação histórica nos mostra que, quando um povo se descura da função legislativa, fazendo suceder leis sôbre leis, este povo ou está decadente ou para decair. As refórmas precipitadas pódem teoricamente ser boas, mas são praticamente nocivas por ainda não terem amadurecido. Roma, no direito privado, e a Inglaterra, no público, são dois admiraveis exemplos de sabedoria e de prudência políticas. Seu patrimônio jurídico surgiu lentamente, sem saltos ou violentas mutações, como o tronco e os ramos de um velho carvalho" (16).

E ainda a alma do jurista que se rebela contra a mística de certas ditaduras.

Sim, caros colegas, o mal não está na ditadura. Certos estados patológicos do organismo social reclamam, como indicação segura e adequada, o remédio drástico de uma ditadura.

Louis LE FUn observou mesmo que "a aparição de um ditador pode ser momentaneamente necessária em certas situações graves, mas ninguém admitirá, sem dúvida, que possa ser o regimen normal para um povo de formação política um pouco adiantada" (17).

Os romanos, este povo admiravel pela sua cultura jurídica, conheciam a ditadura comissária, este regimen anormal para situações anormais.

O mal não está na ditadura, mas na mística que engendra para se perpetuar, esta sim, verdadeiro ópio para o povo, a determinar o colapso da conciência jurídica de uma nação. 
Eis o perigo que a alma do jurista sabe sempre evitar, como ocorre entre nós, em nossa terra, onde a estrutura do direito a três dimensões adquire traços morais e religiosos que constituem "o divino no direito."

o que de vós esperamos, da vossa alma de juristas, forjada no ímo da familia brasileira e retemperada no vosso curso de direito.

Podeis pois partir...

Aqui ou acolá, porém, neste nosso querido São Paulo ou pelo Brasil afóra lembrai-vos que a hora é a do jurista e que, como juristas, tendes uma missão a cumprir. Que a cumprireis, estou certo, mercê do lema com que ungí o vosso quadro de formatura "Nihil volentibus arduum". Aos que sabem querrer como vós, realmente nada é dificil.

Ide, senhores Bachareis, desempenhar a missão que vos assinala, orgulhosa de seus filhos, a velha Faculdade pelo Hino Acadêmico que tanta vez ouvistes sob as Arcadas.

Ide, e que na música imorredoura de Carlos Gomes ressoe sempre em vossos ouvidos, como um estímulo, um incentivo, a palavra ardente de BitTencourt SAMpáo:

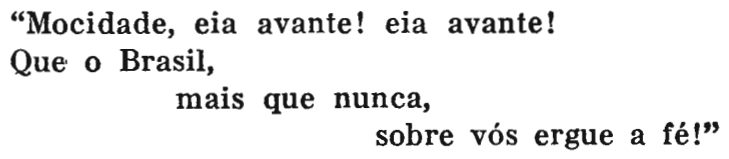

\section{BIBLIOGRAFIA}

$\overline{1}$ - “Academia que é a representação viva do direito nacional...", João Monteiro.

2 - "Digesto Italiano", voc. "Azione".

3 - Claude du Pasquier, "Introduction à la théorie générale et à la philosophie du Droit"

4 - Claude du Pasquier, ob. cit.

5 - Milhaïl Manoülesco, "Le parti unique".

6 - J. Charmont, "La renaissance du Droit Naturel".

7 - "Sintesis", novembro de 1941.

8 - "Tratado de Direito Civil Brasileiro", vol 1, n. 75.

9 - Novitza Kralyevitch, "La porté théorique du glissement du Droit vers la Sociologie" 
10 - ob. cit.

11 - Institut International de Philosophie du Droit, et de Sociologie Juridique, "Travaux de la seconde session".

12 - Wilhelm Sauer, ob. cit.

13 - Trabalhos citados.

14 - "apud" Eduardo Espinola, ob. cit.

15 - Pietro Cogliolo, "Filosofia do Direito Privado".

16 - Ob. cit. 